\title{
AN EXPERIMENTAL DESIGN APPROACH FOR OPTIMIZATION OF MODIFIED COLORIMETRIC FIRST-ORDER DERIVATIVE METHOD FOR ESTIMATION OF SERRALYSIN IN BULK AND PHARMACEUTICAL FORMULATION
}

\author{
KULKARNI MANASI B ${ }^{1 *}$, JOSHI ANAGHA M$^{2}$
}

${ }^{1}$ PhD Scholar, Ponnaiyah Ramajayam Institute of Science and Technology University, Thanjavur, Tamil Nadu, India, ${ }^{2}$ Principal, SCES'S Indira College of Pharmacy, Pune, Maharashtra, India. Email: mansi.wagdarikar@indiraicp.edu.in

Received: 30 April 2018, Revised and Accepted: 29 May 2018

\section{ABSTRACT}

Objective: The aim of the present work is to use experimental design to screen and optimize experimental variables for developing a colorimetric firstorder derivative method for determining content of serralysin (SER) using biuret and Folin-Ciocalteu phenol reagent for stable color development. The method is based on the reaction of peptide bond in the protein with Biuret reagent in alkaline medium and further reaction of remaining tryptophan and tyrosine residues with Folin-Ciocalteu Phenol reagent to form a stable blue-colored complex (first-order derivative $\lambda_{\max } 620 \mathrm{~nm}$ ).

Materials and Methods: A two-level full factorial design was utilized to screen the effect of Volume of NaOH (A), volume of biuret reagent (B), volume of Folin-Ciocalteu phenol reagent (C), and concentration of $\mathrm{NaOH}$ (D) on the formation of blue-colored SER - reagent complex (response - absorbance). A box Behnken experimental design with response surface methodology was then utilized to evaluate the main interaction and quadratic effects of these factors on the selected response.

Results: With the help of a response surface plot and contour plot, the optimum values of the selected factors were determined and used for further experiments. These values were volume of $\mathrm{NaOH}(\mathrm{A})$ of $1.0 \mathrm{~mL}$, volume of biuret reagent (B) of $0.25 \mathrm{~mL}$, and volume of Folin-Ciocalteu phenol reagent (C) of $10 \mu \mathrm{L}$. The proposed method was validated according to the ICH $Q_{2}\left(R_{1}\right)$ method validation guidelines. The developed colorimetric first-order derivative method was found to be simple, accurate, rapid, sensitive, precise, and economic. Further optimization of the method with experimental design approach makes it convenient for use in laboratory.

Conclusion: The results of present study have clearly shown that an experimental design approach may be effectively applied to the optimization of a modified visible spectrophotometric method for estimation of SER in bulk and in pharmaceutical formulation with the least number of experimental runs possible. The method can be employed successfully for the estimation of SER in both bulk and tablet dosage form.

Keywords: Serralysin, Experimental design, Box-Behnken Model, Colorimetric, First-order derivative, Biuret, Folin-Ciocalteu.

(c) 2018 The Authors. Published by Innovare Academic Sciences Pvt Ltd. This is an open access article under the CC BY license (http://creativecommons. org/licenses/by/4. 0/) DOI: http://dx.doi.org/10.22159/ajpcr.2018.v11i9.26999

\section{INTRODUCTION}

Analytical studies, related to the quality control and routine analysis of commercial products in the research or industry laboratories, use spectrophotometric methods such as derivative spectrophotometry. These spectrophotometric methods are found to be preferable instead of hyphenated analytical instrumentations or techniques such as liquid chromatography-mass spectrometry (LC-MS), gas chromatography-MS, LC-nuclear magnetic resonance, etc., which always require prior steps such as extraction and other tedious analytical process during analysis [1].

Serralysin (SER) (CAS registry number: 70851-98-8, EC 3.4.24.40) has a long history in medicine and is widely used to combat various kinds of inflammation and inflammatory disorders. SER is a proteolytic enzyme isolated from the non-pathogenic enterobacteria Serratia E 15 found in silkworms [2]. A recent finding suggests that the enzyme reduces capillary permeability induced by histamine, bradykinin, and serotonin; it dissolves the abnormal exudates and proteins by breaking it down and facilitates the absorption of decomposed products through blood and lymphatics [3]. Thus, SER acts as a potent anti-inflammatory agent. The enzyme has a molecular weight of $45-60 \mathrm{KD}$ and is a metalloprotease containing a zinc atom which is important for its proteolytic activity (Fig. 1).

Implementation of quality by design for analytical methods during development allows for enhanced understanding of the analytical method focusing on robustness and ruggedness, thereby facilitating method transfer and providing opportunities for continual improvement [4]. Two-level full factorial design is used for screening the important factors that influence the response. Factorial designs are advantageous over one factor at a time (OFAT) method as it gives wider inductive basis to draw inferences about the process and it also reveals "interactions" of factors. A two-level full factorial design consists of 2 levels of each experimental factor. It provides direction for further experimentation [5].

Response surface methodology (RSM) is a statistical technique used for the development and optimization of complex processes [6-8]. Different types of response surface designs are used for optimization such as central composite design (CCD) and Box-Behnken design (BBD). The beauty of BBD is that it requires fewer test runs and is rotatable [9].

The BBD is advantageous because it does not contain any points at the extremes of the cubic region created by the two-level factorial combinations $[6,7,10]$. BBD is a second-order quadratic model for non-linear responses which is mainly used when the factor space is within the experimental domain [11]. The BBD was selected in the present investigation and used to optimize and validate a modified spectrophotometric method for estimating SER because the design provides three levels for each factor and requires fewer runs as compared to CCD. 


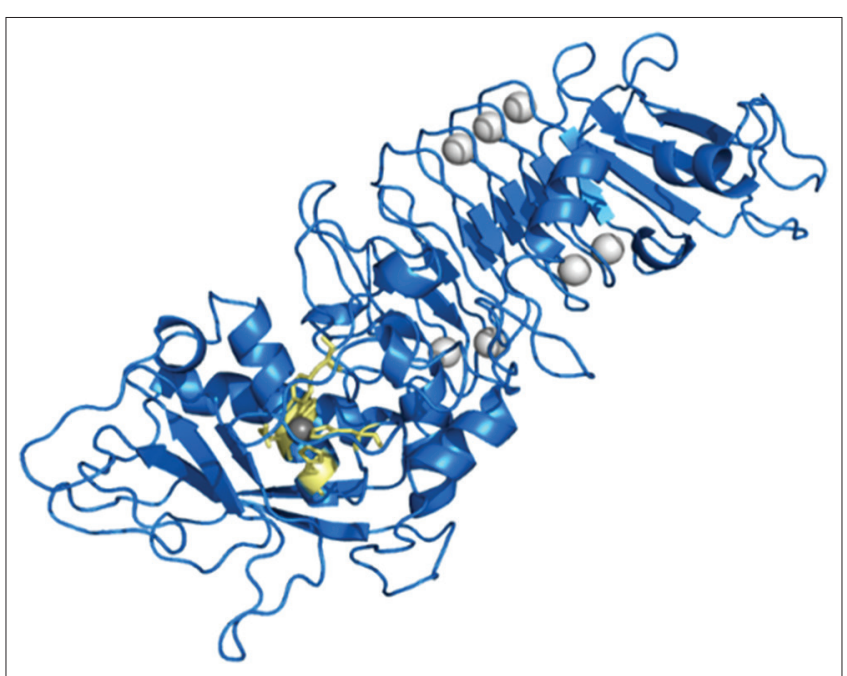

Fig. 1 Serralysin structure

Numerous studies have been carried out for quantitative and qualitative estimation of SER [12]. Thin-layer chromatography [13], SDS-PAGE gel electrophoresis [14], and X-ray powder diffractometry [15] are some of the techniques reported for successful qualitative estimation of SER. Quantitative instrumental methods use chromatography, field flow fractionation, electrophoresis, etc., for separation, and physical properties such as absorption, fluorescence, conductivity, and light scattering are used to measure the analyte accurately and precisely [12]. For quantitative analysis, caseinolytic assay method [16-27], spectroscopy [28-35], fluorescence spectrometry [36], enzyme-linked immunosorbent assay (ELISA) [37-39], radioimmunoassay [40], ultraviolet (UV) microplate method [41], high-performance LC (HPLC) [42], and LC-MS method [43] are reported.

In the reported spectrophotometric methods, the absorbance of SER was measured in the UV region wavelengths. The present study uses a colorimetric first-order derivative analysis of SER in bulk and tablet formulation. For protein quantitation, the biuret method [44-47] and the Lowry method $[48,49]$ have been widely used as standard procedures. The biuret method has a more linear correlation between protein concentration and absorbance but lacks sensitivity. Therefore, the sensitive Lowry method is more preferred. However, the necessity of preparing chemicals for each protein measurement due to poor stability of the combined reagents, instability of color development, the standard curve being non-reproducible, especially at low concentrations and non-linearity between absorbance and protein concentration are some of the problems associated with the Lowry method. In 1976, S. Ohnishi and Barry proposed a simplified method of quantifying protein using the biuret and phenol reagents where the protein sample was first treated with biuret reagent and then with $2 \mathrm{~N}$ Phenol reagent for color development. The method was superior to any of the widely used colorimetric method for protein estimation [50].

In the present work, combined application of the biuret method and the Lowry method in enhanced alkaline conditions is employed. The aim of the present work was to utilize the experimental design approach for screening and optimizing the experimental variables for developing modified colorimetric first-order derivative method for estimation of SER in bulk and pharmaceutical formulation.

\section{EXPERIMENTAL}

\section{Instrument}

A Jasco UV visible spectrophotometer V-730 (Spectra Manager Software) with $1 \mathrm{~cm}$ matched quartz cells was used for measuring absorbance.

\section{MATERIALS AND METHODS}

SER was purchased from Analab Fine chemicals, Mumbai (Maharashtra). Cipzen forte tablets $(10 \mathrm{mg}$ ) and Bidanzen $(5 \mathrm{mg}$ ) were purchased from the local medical shop. Analytical grade chemicals (biuret reagent, sodium hydroxide, Folin-Ciocalteu's phenol reagent) and distilled water were used in the experiments.

\section{Reagents and standards}

Stock biuret reagent from Analab Fine chemicals and Folin-Cioclteu's phenol reagent from MERCK were used for the work. Different concentrations of sodium hydroxide $(0.5 \mathrm{~N}, 1.0 \mathrm{~N}$, and $1.5 \mathrm{~N})$ were prepared according to Indian Pharmacopoeia.

\section{Standard solution for spectrophotometric method}

A stock solution of SER $(2000 \mu \mathrm{g} / \mathrm{mL})$ was prepared by dissolving $0.2 \mathrm{~g}$ in $100 \mathrm{~mL}$ of distilled water.

\section{Sample solution for spectrophotometric method}

Twenty tablets of each brand were weighed and powdered. A quantity of powder equivalent to $10 \mathrm{mg}$ of SER was transferred to $10 \mathrm{~mL}$ distilled water. The solution was sonicated in an ultrasonic bath for $10 \mathrm{~min}$, mixed and filtered using Whatman filter paper.

\section{MATERIALS AND METHODS}

\section{Two-level factorial design}

A two-level full factorial design was employed to evaluate the effects of four independent factors, namely, volume of $\mathrm{NaOH}(\mathrm{A})$, volume of biuret reagent (B), volume of Folin-Ciocalteu phenol reagent (C), and concentration of $\mathrm{NaOH}$ (D) on absorbance R. On the basis of preliminary experiments, the ranges of values used in the design are the following: Volume of $\mathrm{NaOH}(\mathrm{A}): 0.5-1.5 \mathrm{~mL}$, volume of biuret reagent (B): 0.1-0.5 mL, volume of Folin-Ciocalteu phenol reagent (C): 0-10 $\mu \mathrm{L}$ and concentration of $\mathrm{NaOH}$ (D): 0.5-1.5 N. The different levels of the selected factors are presented in Table 1 and the design matrix of the two-level full factorial design is provided in Table 2. All the experimental runs were performed in triplicate and results are presented in Table 2.

\section{Optimization by RSM}

A three-level BBD with three center points (Table 3) was used to evaluate the main, interaction, and quadratic effects of volume of $\mathrm{NaOH}(\mathrm{A})$, volume of biuret reagent (B), and volume of Folin-Ciocalteu phenol reagent $(\mathrm{C})$ on absorbance $\mathrm{R}$. On the basis of results obtained by applying two-level full factorial design, it may be concluded that addition of Folin-Ciocalteu's phenol reagent (C), significantly affects the response absorbance. However, the reproducibility was lost if volume of Folin-Ciocalteu's phenol reagent is increased beyond $12 \mu \mathrm{L}$. Based on this fact, the volume of Folin-Ciocalteau's phenol reagent was optimized within the range 8-12 $\mu \mathrm{L}$. The experimental conditions that were maintained constant include concentration of $\mathrm{NaOH}(0.5 \mathrm{~N})$ and the diluting solvent (distilled water). All the experimental runs were performed in triplicate and the results are presented in Table 3.

\section{Linearity study}

An aliquot of the standard stock solution (3.0-6.0 ml) was transferred to $10 \mathrm{ml}$ volumetric flask. The total volume of each flask was brought to $10 \mathrm{ml}$ with distilled water. $1.0 \mathrm{ml}$ of $0.5 \mathrm{~N} \mathrm{NaOH}$ was added to each flask. The solutions were kept aside for $5 \mathrm{~min} .0 .25 \mathrm{ml}$ of biuret reagent was then added in each flask and solution was thoroughly mixed on vortex for 5 min reaction time. Then, $10 \mu \mathrm{L}$ of Folin-Ciocalteu's phenol reagent was added and reaction mixture was again mixed for $1 \mathrm{~min}$. The blue-colored reaction solution was scanned in the range of 400-800 nm against reagent blank. The spectra were converted in first-order derivative form and absorbances were measured at $\lambda_{\max } 620 \mathrm{~nm}$. (Fig. 2)

\section{Assay of SER in pharmaceutical formulation}

Aliquots of about 3 and $10 \mathrm{ml}$ of the standard stock and sample solutions were transferred to $10 \mathrm{ml}$ volumetric flask. The total volume of standard was brought to $10 \mathrm{ml}$ with distilled water. $1 \mathrm{ml}$ of $0.5 \mathrm{~N}$ 
Table 1: Experimental factors and response variable for two-level full factorial design

\begin{tabular}{|c|c|c|c|c|c|}
\hline Factor & Name & Units & Type & Minimum & Maximum \\
\hline A & Volume of $\mathrm{NaOH}$ & $\mathrm{ml}$ & Numeric & 0.5 & 1.5 \\
\hline B & Volume of biuret reagent & $\mathrm{ml}$ & Numeric & 0.1 & 0.5 \\
\hline $\mathrm{C}$ & Volume of Folin-Ciocalteu's phenol reagent & $\mu \mathrm{L}$ & Numeric & 0 & 10 \\
\hline $\mathrm{D}$ & concentration of $\mathrm{NaOH}$ & $\mathrm{N}$ & Numeric & 0.5 & 1.5 \\
\hline Response R & Absorbance & Abs units & Goal maximum & & \\
\hline
\end{tabular}

Table 2: Experiment $2^{4}$ and response value

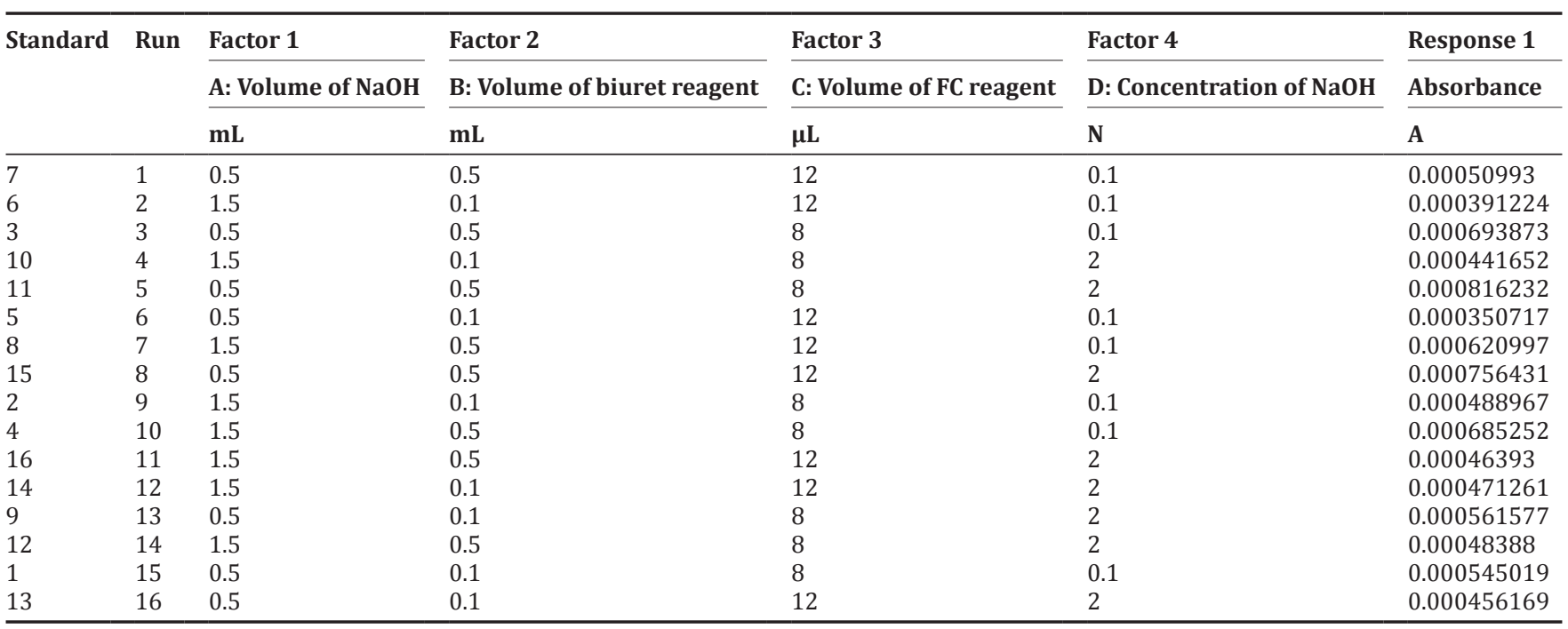

Table 3: Optimization method parameters for Box-Behnken experimental design

\begin{tabular}{|c|c|c|c|c|c|}
\hline Run & A: Volume of $\mathrm{NaOH}$ & $\begin{array}{l}\text { B: Volume of biuret } \\
\text { reagent }\end{array}$ & $\begin{array}{l}\text { C: Volume of Folin-Ciocalteu's } \\
\text { phenol reagent }\end{array}$ & Predicted response & Observed response $R$ \\
\hline 1 & 0.5 & 0.25 & 12 & 0.087 & 0.080 \\
\hline 2 & 1 & 0.4 & 8 & 0.077 & 0.072 \\
\hline 3 & 1 & 0.25 & 10 & 0.096 & 0.095 \\
\hline 4 & 0.5 & 0.4 & 10 & 0.068 & 0.071 \\
\hline 5 & 0.5 & 0.25 & 8 & 0.077 & 0.079 \\
\hline 6 & 1 & 0.25 & 10 & 0.096 & 0.092 \\
\hline 8 & 1 & 0.1 & 12 & 0.063 & 0.068 \\
\hline 9 & 1 & 0.4 & 12 & 0.078 & 0.082 \\
\hline 10 & 1 & 0.25 & 10 & 0.096 & 0.098 \\
\hline 11 & 1 & 0.25 & 10 & 0.096 & 0.097 \\
\hline 12 & 1.5 & 0.25 & 12 & 0.083 & 0.081 \\
\hline 13 & 1.5 & 0.4 & 10 & 0.075 & 0.073 \\
\hline 14 & 1.5 & 0.1 & 10 & 0.048 & 0.045 \\
\hline 15 & 0.5 & 0.1 & 10 & 0.054 & 0.056 \\
\hline 17 & 1.5 & 0.25 & 8 & 0.082 & 0.090 \\
\hline
\end{tabular}

$\mathrm{NaOH}$ was added to each flask. The solutions were kept aside for 5 min. $0.25 \mathrm{ml}$ of biuret reagent was then added in each flask and solutions were mixed on vortex mixer for 5 min reaction time. Then, $10 \mu \mathrm{L}$ of Folin-Ciocalteu's phenol reagent was added and reaction mixture was again mixed for $1 \mathrm{~min}$. The spectra for standard and sample solutions were converted into first-order derivative spectra and absorbances were measured at $620 \mathrm{~nm}$. The content of SER in the pharmaceutical dosage form was calculated using the following formulae:

$$
\begin{aligned}
& \mathrm{X}_{\text {Est }}=\frac{\left(\mathrm{A}_{\text {Sample }} \times \mathrm{W}_{\text {Std }} \times \mathrm{W}_{\text {Avg }}\right)}{\mathrm{A}_{\text {Std }} \times \mathrm{W}_{\text {Sample }}} \\
& \text { \%LabelClaim }=\frac{\mathrm{X}_{\text {Est }}}{\mathrm{X}_{\text {LABELCLAIM }}} \times 100
\end{aligned}
$$

where $\mathrm{X}_{\mathrm{Est}}=$ content of SER per tablet of average weight; $\mathrm{A}_{\text {Sample }}=$ absorbance of sample solution; $\mathrm{A}_{\mathrm{std}}=$ absorbance of standard solution; $\mathrm{W}_{\text {Std }}=$ weight of standard (mg); $\mathrm{W}_{\text {Sample }}=$ weight of sample (mg); and $\mathrm{X}_{\text {LABEL CLAIM }}=$ labeled content of SER per tablet $(\mathrm{mg})$.

\section{RESULTS AND DISCUSSION}

A colorimetric derivative spectrophotometric method was developed and optimized for determining the content of SER using the biuret reagent and Folin-Ciocalteu's phenol reagent for stable and reproducible color development. The use of both the reagents together improves the absorbance. The conversion in first-order derivative spectra is needed for better linearity. The experimental design approach was utilized for screening and optimizing the experimental variables of the first-order derivative spectrophotometric method. 
Two-level full factorial design

Factorial design is a tool that allows us to experiment on many factors simultaneously. In proposed work, a two-level full factorial design was utilized to evaluate the main effect of four independent factors on the selected response R. The primary purpose was to identify significant main effects with the minimum number of experimental runs as possible.

The effects of all factors included in the experimental design on selected response $\mathrm{R}$ are shown in Table 2. An effect was considered to be significant at $\mathrm{p} \leq 0.05$. The significant factor is the influencing factor. The effect of each factor was interpreted as the average change in response $\mathrm{R}$ as the factor changed from low to high level (Table 1). Pareto ranking analysis revealed that the factors that were statistically significant $(\mathrm{p} \leq 0.05)$ for selected response $\mathrm{R}$ were the volume of $\mathrm{NaOH}(\mathrm{A})$, volume of biuret reagent (B) and volume of Folin-Ciocalteau's phenol reagent (C). The Pareto charts (Fig. 3) gives vital few effects on left and trivial many at right. The length of each bar in Pareto chart is equivalent to the magnitude of the regression coefficients of the factor. The volume of $\mathrm{NaOH}(\mathrm{A})$, volume of biuret reagent (B), and volume of Folin-Ciocalteu's phenol reagent $(\mathrm{C})$ have direct relationships with the absorbance $\mathrm{R}$ and their effects are statistically significant $(p \leq 0.05)$. The Concentration of $\mathrm{NaOH}$ (D) also has a direct effect on the selected response R, but this is not statistically significant $(\mathrm{p}>0.05)$.

\section{Box-Behnken experimental design}

Using multivariate regression analysis, a fitted full quadratic model was obtained for the average response $\mathrm{R}$, given by following equation:

$\mathrm{R}=\beta_{0}+\beta_{1} \mathrm{~A}+\beta_{2} \mathrm{~B}+\beta_{3} \mathrm{C}+\beta_{11} \mathrm{~A}^{2}+\beta_{22} \mathrm{~B}^{2}+\beta_{33} \mathrm{C}^{2}+\beta_{12} \mathrm{AB}+\beta_{13} \mathrm{AC}+\beta_{23} \mathrm{BC}$

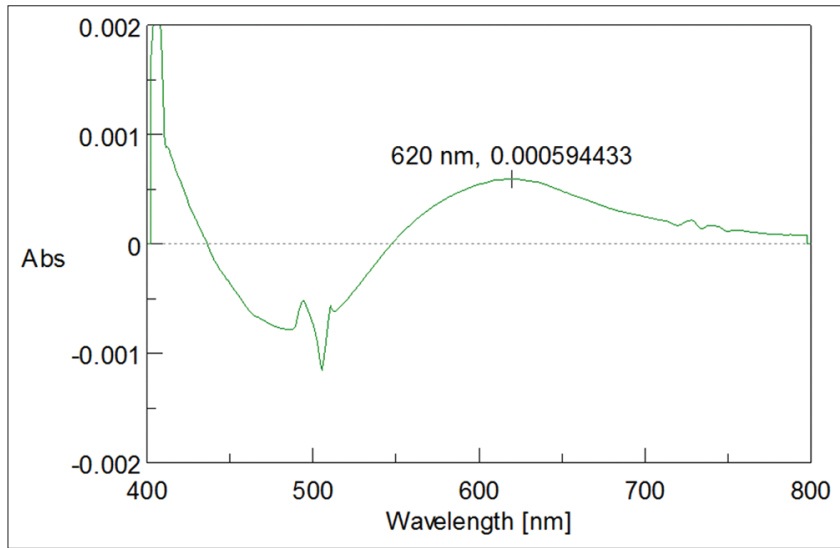

Fig. 2: First-order derivative spectra of standard serralysin in visible range after reaction with biuret reagent and FolinCiocalteau's reagent

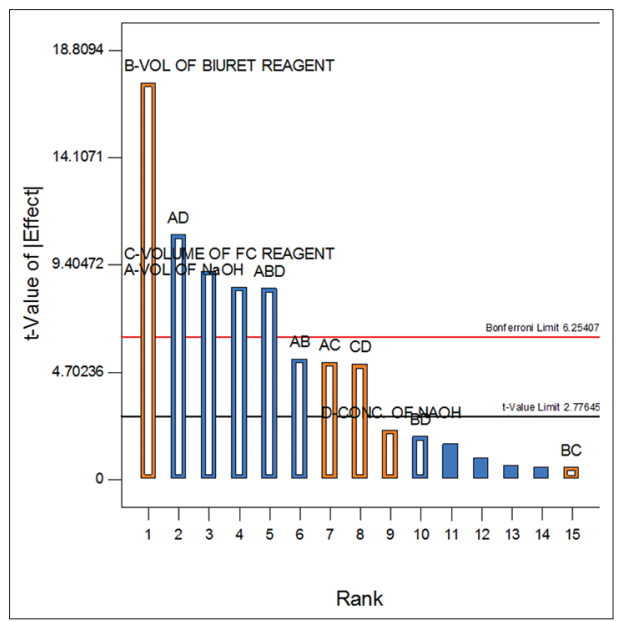

Fig. 3: Pareto chart of effects where $\mathrm{R}=$ Selected response; $\beta_{0}=$ arithmetic mean response; and $\beta_{1}, \beta_{2}$, and $\beta_{3}=$ regression coefficients of the factors $A, B$, and $C$, respectively.

Tables 4 and 5 have shown the values of regression coefficients and their associated p-values. It may be observed that volume of $\mathrm{NaOH}(\mathrm{A})$, volume of biuret reagent (B), and volume of Folin-Ciocalteau's phenol reagent (C) significantly affected the absorbance (R) of colored complex $(p<0.05)$. An interaction was observed between the volume of $\mathrm{NaOH}(\mathrm{A})$ and volume of biuret reagent (B) ( $p=0.3351)$, between volume of $\mathrm{NaOH}$ $(A)$ and volume of Folin-Ciocalteu's phenol reagent (C) $(p=8039)$ and it was also observed between volume of Biuret reagent (B) and volume of Folin-Ciocalteu's phenol reagent (C) $(p=0.3724)$, but these interactions are found to be insignificant as $\mathrm{p}>0.05$. Volume of biuret reagent was found to affect the response more. An interaction plot is shown in Fig. 4.

Response surface and contour plots were also analyzed to visualize the effects of the parameters on the selected response R. Fig 4 shows the effects of volume of $\mathrm{NaOH}(\mathrm{A})$, volume of biuret reagent (B), and volume of Folin-Ciocalteau's phenol reagent (C) on the selected response R.

It may be interpreted from the surface diagram that volume of biuret reagent $(B)$ was in the range of $0.24-0.26 \mathrm{ml}$ and that a volume of $\mathrm{NaOH}$ (A) in the range of 1.0-1.1 ml gives maximum absorbance (R) (Fig. 5a).

A volume of $\mathrm{NaOH}(\mathrm{A})$ was in the range of $1.0-1.1 \mathrm{ml}$ and that a volume of Folin-Ciocalteu phenol reagent $(\mathrm{C})$ in the range of $10-12 \mu \mathrm{L}$ gives maximum absorbance (R) (Fig. 5b)

A volume of Folin-Ciocalteu phenol reagent (C) was in the range of $10-12 \mu \mathrm{L}$ and that a volume of biuret reagent (B) in the range of 0.25$0.28 \mathrm{ml}$ gives maximum absorbance (R) (Fig. $5 \mathrm{c}$ ).

\section{Model validation}

The experimental results and the predicted values obtained using polynomial model show that the predicted values match the selected response $\mathrm{R}$ reasonably with an $\mathrm{R}^{2}$ of $96.65 \%$ and an $\mathrm{R}^{2}$ (adj) of $95.35 \%$.

Fig. 6 shows the residual plots of the selected response $\mathrm{R}$ in model equation. The distribution of the residuals of the response approximately follows the fitted normal distribution, whereas the

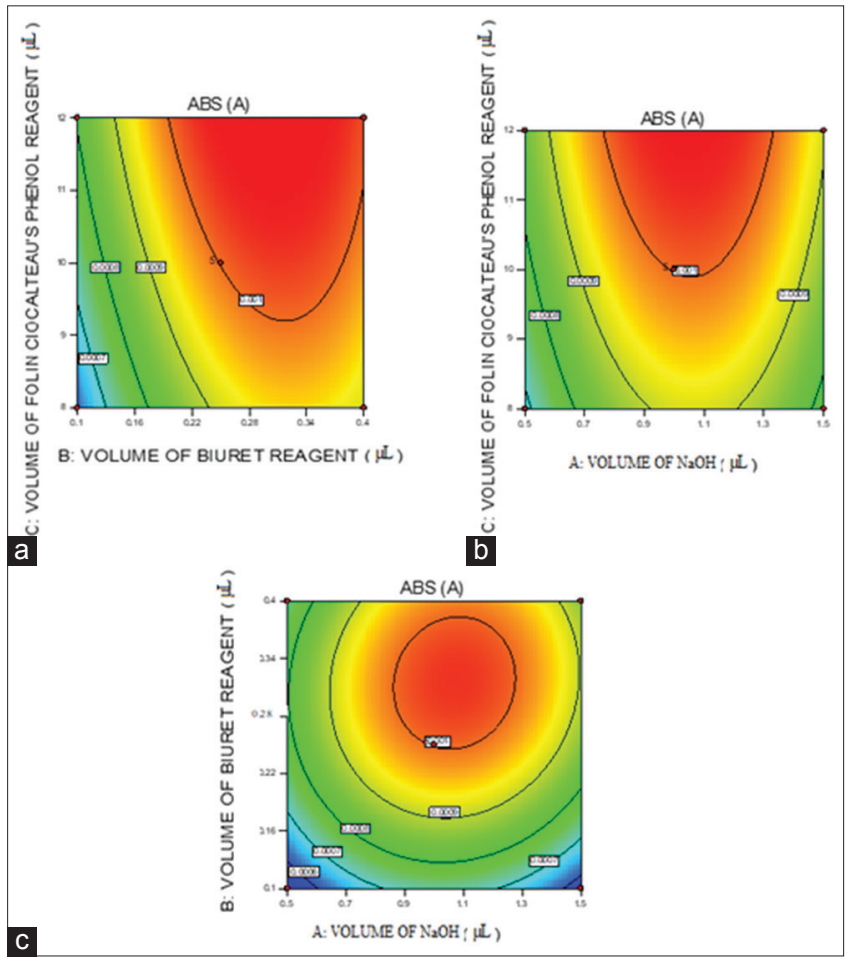

Fig. 4: (a-c) Interaction plot of response $R$ 
Table 4: Analysis of variance for selected response

\begin{tabular}{|c|c|c|c|c|c|c|}
\hline Source & Sum of squares & df & Mean square & $\boldsymbol{F}$ & $\mathbf{p}>\mathbf{F}$ & Inference \\
\hline Model & $4.372 \mathrm{E}-007$ & 9 & $4.858 \mathrm{E}-008$ & 22.46 & 0.0002 & Significant \\
\hline A-volume of $\mathrm{NaOH}$ & $1.295 \mathrm{E}-008$ & 1 & $1.295 \mathrm{E}-008$ & 5.98 & 0.0443 & \\
\hline B-volume of biuret reagent & $1.252 \mathrm{E}-007$ & 1 & $1.252 \mathrm{E}-007$ & 57.88 & 0.0001 & \\
\hline C-volume of Folin-Ciocalteau's phenol reagent & $4.221 \mathrm{E}-008$ & 1 & $4.221 \mathrm{E}-008$ & 19.51 & 0.0031 & \\
\hline $\mathrm{AB}$ & $2.317 \mathrm{E}-009$ & 1 & 2.317E-009 & 1.07 & 0.3351 & \\
\hline $\mathrm{AC}$ & $1.438 \mathrm{E}-010$ & 1 & $1.438 \mathrm{E}-010$ & 0.066 & 0.8039 & \\
\hline $\mathrm{BC}$ & $1.964 \mathrm{E}-009$ & 1 & $1.964 \mathrm{E}-009$ & 0.91 & 0.3724 & \\
\hline $\mathrm{B}^{2}$ & $9.384 \mathrm{E}-008$ & 1 & $9.384 \mathrm{E}-008$ & 43.38 & 0.0003 & \\
\hline $\mathrm{C}^{2}$ & 1.157E-009 & 1 & 1.157E-009 & 0.53 & 0.4884 & \\
\hline Residual & $1.514 \mathrm{E}-008$ & 7 & 2.163E-009 & & & \\
\hline Lack of fit & $9.025 \mathrm{E}-009$ & 3 & $3.008 \mathrm{E}-009$ & 1.97 & 0.2611 & Not significant \\
\hline Pure error & $6.118 \mathrm{E}-009$ & 4 & 1.529E-009 & & & \\
\hline Total & $4.524 \mathrm{E}-007$ & 16 & & & & \\
\hline
\end{tabular}

Table 5: Estimated regression coefficient for selected response

\begin{tabular}{|c|c|c|c|c|c|}
\hline Factor & Coefficient estimate & df & SE & $95 \%$ CI low & 95\% CI high \\
\hline Intercept & $1.002 \mathrm{E}-003$ & 1 & $2.080 \mathrm{E}-005$ & $9.525 \mathrm{E}-004$ & $1.051 \mathrm{E}-003$ \\
\hline A-volume of $\mathrm{NaOH}$ & 4.023E-005 & 1 & $1.644 \mathrm{E}-005$ & $1.344 \mathrm{E}-006$ & 7.911E-005 \\
\hline B-volume of biuret reagent & $1.251 \mathrm{E}-004$ & 1 & $1.644 \mathrm{E}-005$ & 8.622E-005 & $1.640 \mathrm{E}-004$ \\
\hline C-volume of Folin-Ciocalteau's phenol reagent & 7.264E-005 & 1 & $1.644 \mathrm{E}-005$ & $3.376 \mathrm{E}-005$ & $1.115 \mathrm{E}-004$ \\
\hline $\mathrm{AB}$ & $2.407 \mathrm{E}-005$ & 1 & $2.326 \mathrm{E}-005$ & $-3.092 \mathrm{E}-005$ & $7.906 \mathrm{E}-005$ \\
\hline $\mathrm{AC}$ & $-5.996 \mathrm{E}-006$ & 1 & $2.326 \mathrm{E}-005$ & $-6.099 \mathrm{E}-005$ & 4.899E-005 \\
\hline $\mathrm{BC}$ & $-2.216 \mathrm{E}-005$ & 1 & $2.326 \mathrm{E}-005$ & $-7.715 \mathrm{E}-005$ & 3.283E-005 \\
\hline $\mathrm{B}^{2}$ & $-1.493 \mathrm{E}-004$ & 1 & $2.267 \mathrm{E}-005$ & $-2.029 \mathrm{E}-004$ & $-9.569 E-005$ \\
\hline $\mathrm{C}^{2}$ & $-1.658 \mathrm{E}-005$ & 1 & $2.267 \mathrm{E}-005$ & $-7.017 \mathrm{E}-005$ & $3.702 \mathrm{E}-005$ \\
\hline
\end{tabular}

$\mathrm{SD}=4.651 \mathrm{E}-005$, Press $=1.540 \mathrm{E}-007, \mathrm{R}^{2}=0.9665$, adjusted $\mathrm{R}^{2}=0.9535$, predicted $\mathrm{R}^{2}=0.6597$. SD: Standard deviation, $\mathrm{SE}$ : Standard error, $\mathrm{CI}$ : Confidence interval

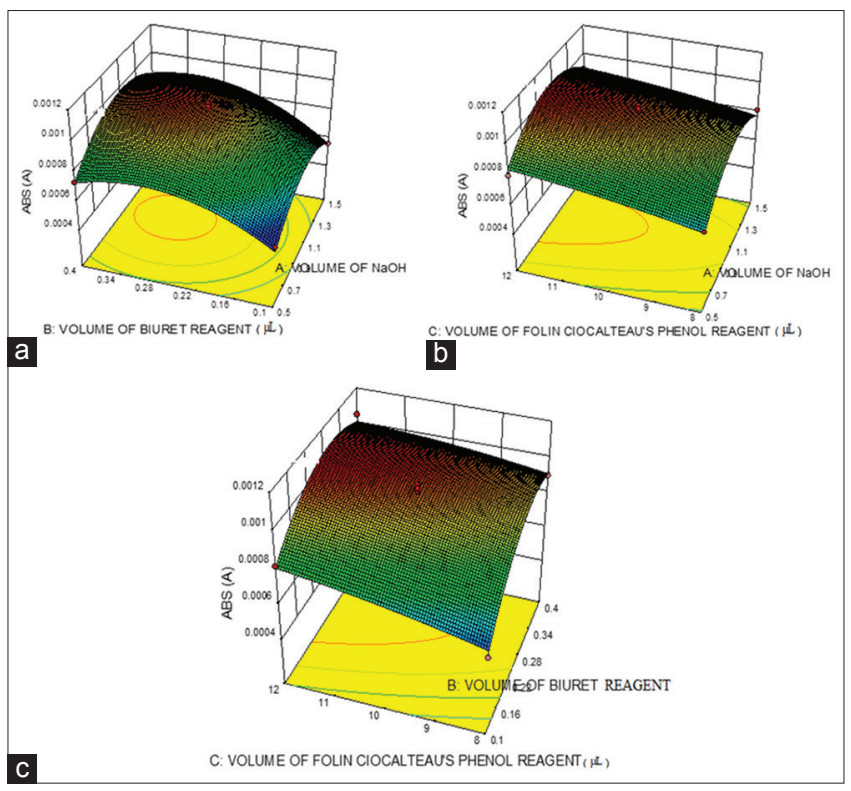

Fig. 5: Response surface plot of response R (a) A: Volume of $\mathrm{NaOH}$ versus B: Volume of Biuret reagent, (b) A: Volume of $\mathrm{NaOH}$ versus C: Volume of Folin-Ciocalteu's phenol reagent, (c) B: Volume of biuret reagent versus C: Volume of Folin-Ciocalteu's phenol reagent

residuals of the response are randomly scattered in the residual plots.

\section{Reaction mechanism}

The proposed method involves copper chelation chemistry. The assay is performed in two distinct steps. In the first step, the protein reacts with Biuret reagent to form a tetradentate copper complex from four peptide bonds and one atom of copper. Second, a reaction with Folin-Ciocalteu's phenol reagent in which a phosphomolybdicphosphotungstic acid solution is added. This compound (called Folinphenol reagent) becomes reduced and produces intense blue color. It is believed that the color enhancement occurs when the tetradentate copper complex transfers electrons to the phosphomolybdicphosphotungstic acid complex. Addition of $\mathrm{NaOH}$ makes the solution more alkaline and this is observed to enhance the color intensity and its stability.

\section{Spectral characteristics}

The scanning speed of $1000 \mathrm{~nm} / \mathrm{min}$, data interval $0.5 \mathrm{~nm}$, and UV response 0.96 seconds were selected as the instrumental parameters by OFAT method. The colored complex formed was observed to give a peak at $620 \mathrm{~nm}$ in the first-order derivative UV spectra when run against reagent blank prepared in similar manner except SER.

\section{Choice of solvent for preparation of SER solution}

Distilled water was selected as solvent for preparing SER solution considering solubility and stability.

\section{Reagent solution}

The Biuret reagent was used without dilution. The Folin-Ciocalteu's reagent $2 \mathrm{~N}$ was used in the assay.

\section{Linearity study}

A calibration graph of the SER concentration versus the absorbance was constructed for the method under optimized conditions. A linear relationship was observed in the concentration range of $0.1-4.0 \mathrm{mg} / \mathrm{ml}$. The graph shows a good correlation coefficient $\left(r^{2}=0.9995\right)$ with the intercept (0.001) calculated using regression equation (Table 6)

\section{Assay results of SER in pharmaceutical formulations}

The results obtained from the analysis of marketed formulations are provided in Table 7. The percent purities of marketed formulations, namely, Bidanzen $(5 \mathrm{mg}$ ) and Cipzen forte $(10 \mathrm{mg}$ ) tablet were found to be $99.50 \pm 0.34$ and $100.60 \pm 0.41$, respectively. 


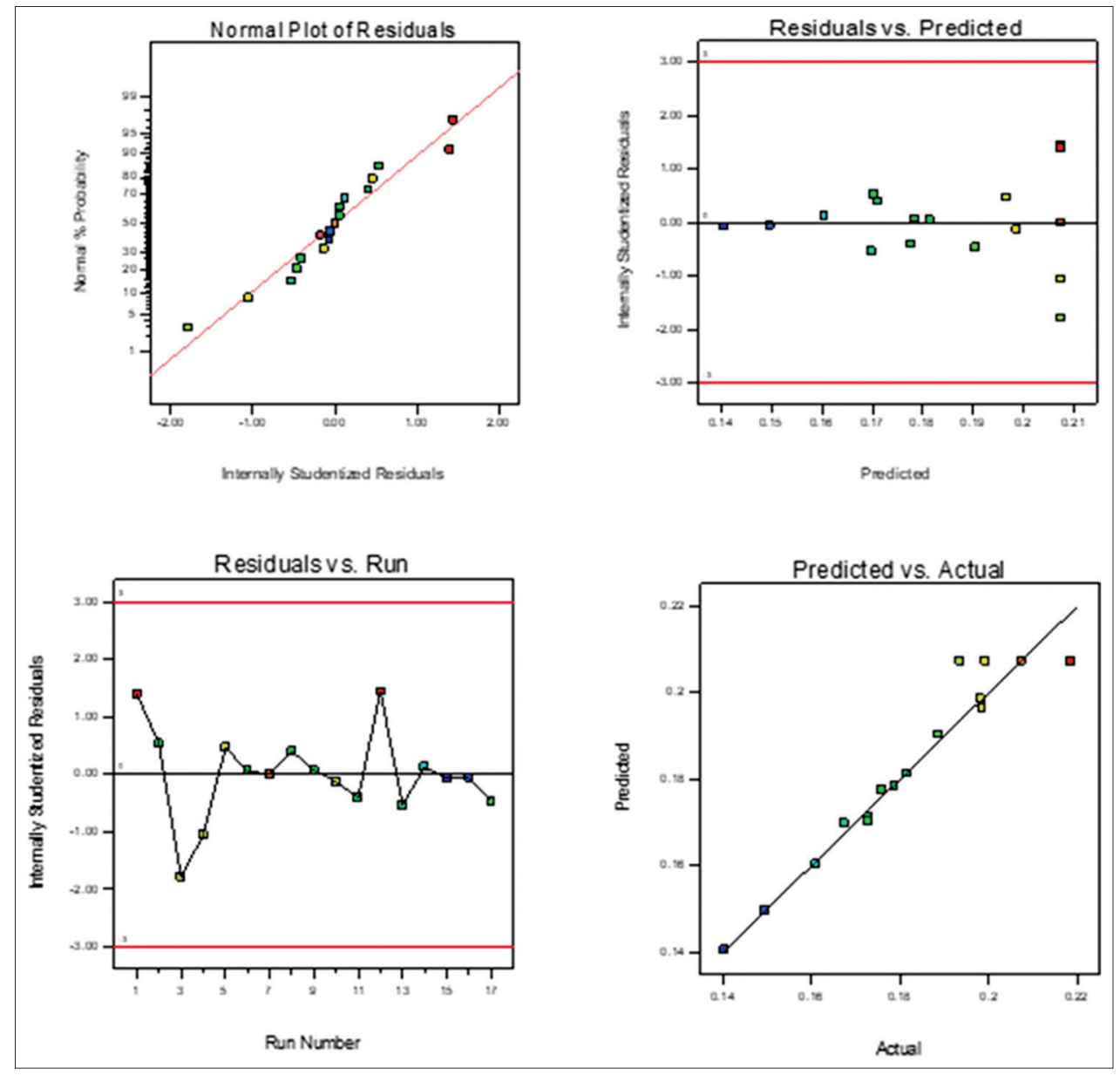

Fig. 6 Residual plots of response $R$

Table 6: Optical characteristics and statistical data of regression equations for the color reaction

\begin{tabular}{ll}
\hline Parameter & SER color complex \\
\hline $\mathrm{pH}$ & Alkaline $(\sim 12.7)$ \\
Colour & Intense blue \\
Derivative $\lambda_{\max }$ & $620 \mathrm{~nm}$ \\
Beer Lambert's law limit $(\mathrm{mg} / \mathrm{ml})$ & $0.1-4.0$ \\
Sandell's sensitivity $(\mathrm{mg} / \mathrm{ml} \mathrm{cm})$ & 1.1 \\
Slope & 0.0009 \\
Intercept & $5 \mathrm{E}-05$ \\
Regression coefficient & 0.9903 \\
\hline
\end{tabular}

SER: Serralysin

Table 7: Determination of serralysin in pharmaceutical formulation

\begin{tabular}{|c|c|c|c|c|}
\hline \multirow[t]{2}{*}{ Label claim } & \multicolumn{4}{|c|}{ Amount of drug founded $(\mathrm{mg}) \pm \% \operatorname{RSD}(n=5)$} \\
\hline & $\begin{array}{l}\text { Proposed } \\
\text { method }\end{array}$ & $\begin{array}{l}\text { Reported } \\
\text { method }\end{array}$ & $\mathbf{t}^{\mathrm{a}}$ & $\mathbf{F}^{\mathbf{b}}$ \\
\hline $\begin{array}{l}\text { Bidanzen } \\
(5 \mathrm{mg})\end{array}$ & $99.50 \pm 0.34$ & $100.43 \pm 0.32$ & 1.7548 & 0.7275 \\
\hline $\begin{array}{l}\text { Cipzen forte } \\
(10 \mathrm{mg})\end{array}$ & $100.60 \pm 0.41$ & $100.98 \pm 0.62$ & 1.2811 & 0.7152 \\
\hline
\end{tabular}

\section{Accuracy}

The accuracy of the proposed method was determined through a recovery study. A known amount of pure SER was used to spike to pre- analyzed tablet formulation. Analysis of SER was carried out at three concentration levels $(80 \%, 100 \%$, and $120 \%)$ within the specified linearity range. Determination of the SER content was carried out using the formula mentioned in the section titled "assay of SER in pharmaceutical formulations." The percent recovery of the proposed method was calculated using the formula as below.

$\%$ Recovery $=\frac{\mathrm{E}}{\mathrm{T}+\mathrm{P}} \times 100$

where $\mathrm{E}=$ total amount of ser estimated (mg); $\mathrm{T}=$ amount of SER from pre-analysis of the tablet powder (mg); and P = amount of pure SER added (mg). The average percent recoveries for Bidanzen $(5 \mathrm{mg})$ and Cipzen forte $(10 \mathrm{mg})$ tablet are found to be $101.02 \pm 0.64$ and $100.70 \pm 0.41$, respectively (Table 8).

\section{Precision}

The interday precision and intraday precision of the method were determined. A repeatability study (intraday precision) was performed by analyzing a sample of SER repeatedly within a day. An interday precision study was performed by analyzing a sample of SER repeatedly at different days. The results of interday and intraday precision were expressed as \%RSD and they were found to be 0.93 and 1.15 , respectively. The $\%$ RSD value indicates that the method has good precision.

\section{Limit of detection (LOD) and limit of quantitation (LOQ)}

The LOD and LOQ of the analytical method developed for estimating the SER content were calculated using the following formulae.

$\mathrm{LOD}=(3.3 \times \sigma) / \mathrm{S}$ 
Table 8: Results of recovery studies by the standard addition method

\begin{tabular}{|c|c|c|c|c|}
\hline Amount of drug in tablet (mg) & $\begin{array}{l}\text { Amount of pure drug } \\
\text { spiked (mg) }\end{array}$ & Total found (mg) & $\begin{array}{l}\text { Recovery of pure drug } \\
\text { added (\%) }\end{array}$ & $\% \operatorname{RSD}(n=3)$ \\
\hline \multicolumn{5}{|l|}{ Bidanzen (5 mg) } \\
\hline 5 & 3 & 8.12 & 104 & 0.95 \\
\hline 5 & 5 & 10.58 & 111.60 & 0.43 \\
\hline 5 & 7 & 12.24 & 103.42 & 0.76 \\
\hline Mean & & & 106.34 & 0.71 \\
\hline \multicolumn{5}{|l|}{ Cipzen forte (10 mg) } \\
\hline 10 & 8 & 18.25 & 103.12 & 1.31 \\
\hline 10 & 10 & 20.41 & 104.10 & 0.37 \\
\hline 10 & 12 & 22.31 & 102.58 & 0.29 \\
\hline Mean & & & 103.26 & 0.65 \\
\hline
\end{tabular}

RSD: Ratio of the standard deviation

$\mathrm{LOQ}=((10 \times \sigma) / \mathrm{S}$

where $\sigma=$ standard deviation of the response; and $\mathrm{S}=$ slope of calibration curve.

The LOD and limit of quantitation were found to be 1.2045 and $4.2136 \mathrm{mg} / \mathrm{mL}$, respectively.

\section{Stability of solution}

The solution used in the precision study was stored for $24 \mathrm{~h}$ at room temperature. During the storage period, the absorbance of the solution was measured after different time intervals $(0,15,30 \mathrm{~min}, 1,2,3,4,5,6$, and $24 \mathrm{~h}$ ), and it was found that the color intensity of the solution was stable up to $6 \mathrm{~h}$.

\section{Statistical analysis of data}

The validity of the proposed method for determining the SER content in pharmaceutical formulations was tested by analyzing the SER using a previously developed HPLC method. The results of the statistical comparison are given in Table 7 . At the 95\% confidence level, the calculated t-value and F-value do not exceed the theoretical values for either Bidanzen ( $5 \mathrm{mg}$ ) or Cipzen forte $(10 \mathrm{mg}$ ) tablet. Therefore, there is no significant difference between the proposed and reported methods, indicating that the proposed method is as accurate and precise as the reported method.

\section{CONCLUSION}

A two-level full factorial design was used to design an experimental program to extract data regarding influencing factors that had significant effects on the selected response (R). One-way ANOVA and Pareto ranking analyses showed that the volume of $\mathrm{NaOH}(\mathrm{A})$, volume of biuret reagent (B) and volume of Folin-Ciocalteu's phenol reagent $(C)$ were statistically significant factors $(\mathrm{p}<0.05)$ affecting the formation of the colored complex of SER and absorbance (R). A BoxBehnken experimental design with RSM was then utilized to evaluate the main, interaction, and quadratic effects of these three factors on the selected response Y. With the help of a response surface plot and contour plot, the optimum values of the selected factors were identified. The predicted values of the response matched the experimental values reasonably well, with an $\mathrm{R}^{2}$ of $96.65 \%$ and an $\mathrm{R}^{2}$ (adj) of $95.35 \%$ for the selected response $\mathrm{R}$. In order to gain a better understanding of the effects of the variables on the selected response $R$, the predicted model was presented in the form of a response surface and contour plot design. It was concluded that the experimental design concept could be effectively used to optimize a visible spectrophotometric method for estimating the SER content in bulk and pharmaceutical formulations with the least number of experimental runs possible.

\section{AUTHOR'S CONTRIBUTION}

Both the authors have contributed for the concept, experimental work, data analysis, and manuscript preparation of the presented research work.

\section{CONFLICTS OF INTEREST}

We declare that there is no conflict of interest.

\section{REFERENCES}

1. Lotfy HM, Saleh SS. Recent development in ultraviolet spectrophotometry through the last decade (2006-2016): A review. Int J Pharm Pharm Sci 2016;8:40-56.

2. Tiwari M. The role of Serralysin in the resolution of inflammation. Asian J Pharm Sci 2017;12:209-15.

3. Nakamura S, Hashimoto Y, Mikami M, Yamanaka E, Soma T, Hino M, et al. Effect of the proteolytic enzyme serrapeptase in patients with chronic airway disease. Respirology 2003;8:316-20.

4. Jadhav ML, Tambe SR, Girase MV. Analytical quality by design approach for development of UV spectrophotometric methods in the estimation of trospium chloride from capsule dosage form. Int J Pharm Pharm Sci 2014;6:530-3.

5. Anderson MJ, Whitcomb PJ. DOE Simplified-Practical Tools for Effective Experimentation. $3^{\text {rd }}$ ed. Taylor and Francis Group: CRC Press; 2015.

6. Ferreira SL, Bruns RE, Ferreira HS, Matos GD, David JM, Brandão GC, et al. Box-behenken design: An alternative for the optimization of analytical methods. Anal Chim Acta 2007;597:179-86.

7. Bezerra MA, Santelli RE, Oliveira EP, Villar LS, Escaleira LA. Response surface methodology (RSM) as a tool for optimization in analytical chemistry. Talanta 2008;76:965-77.

8. Wani YB, Patil DD. An experimental design approach for optimization of spectrophotometric method for estimation of cefiximetrihydrate using ninhydrin as derivatizing reagent in bulk and pharmaceutical formulation. J Saudi Chem Soc 2017;21:S101-11.

9. Anderson MJ, Whitcomb PJ. RSM Simplified-Optimizing Processes using response Surface Methods for Design of Experiments. Special Indian Edition. Taylor and Francis Group: CRC Press; 2016.

10. Box GP, Behenken DW. Some new three level designs for the study of quantitative variables. Technometrics 1960;2:455-75.

11. Patravale VB, Disouza JI, Rustomjee MT. Pharmaceutical Product Development. Taylor and Francis Group: CRC Press; 2016.

12. Gupte V, Luthra U. Analytical techniques for Serralysin - A review. J Pharm Anal 2017;7:203-7.

13. Kyoko T, Keiko M, Kayoko S. Quality tests of high molecular weight substances by chromatography. ByoinYakugaku 1981;6:233-7.

14. Ananthkrishnan A, Ramesh B, Muthuraman MS. Optimization studies in the production and purification of Serralysin from Serratia marcescens UV mutant SM3. Int J Pharm Pharm Sci 2013;5:748-52.

15. Kazuyuki S, Yoshifumi M, Etsuko M. Application of X-Ray powder diffractionto drug information and dispensing services. II. Identification of ingredients in powder preparations containing composite powder like granules and pulverized tablets (or capsules). Byoin Yakugaku 1992;18:700-9.

16. Tariq AL, Reyaz AL, Prabakaran JJ. Purification and characterization of 56 KDa cold active protease from Serratia marcescens. Afr J Microbiol Res 2011;5:5841-7.

17. Abou EM. Purification and characterization of protease produced by Pseudomonas aeruginosa, Egypt. J Microbiol 1997;31:323-35.

18. Salamone PR, Wodzinski RJ. Production, purification and characterization of a $50-\mathrm{kDa}$ extracellular metalloprotease from Serratia marcescens. Appl Microbiol Biotechnol 1997;48:317-24.

19. Zeng W, Chen L, Deng Z. Determination of enzymic activity of 
serralysin in seradase enterosoluble tablets. Guangdong Yaoxueyuan Xuebao 1997;13:81-3.

20. Pansuriya RC, Singhal RS. Evolutionary operation (EVOP) to optimize whey independent serralysin production from Serratia marcescens NRRL B-23112. J Microbiol Biotechnol 2010;20:950-7.

21. Mali N, Wavikar P, Vavia P. Serratiopeptidase loaded chitosan nanoparticles by polyelectrolyte complexation: In vitro and in vivo evaluation. AAPS PharmSciTech 2015;16:59-66.

22. Maheshwari M, Miglani G, Mali A, Paradkar A, Yamamura S, Kadam S. Development of tetracycline-serratiopeptidase-containing periodontal gel: Formulation and preliminary clinical study. AAPS PharmSciTech 2006;7:76

23. Singh KP, Chhabra G, Sharma V, Pathak K. Thermosensitive periodontal sol of ciprofloxacin hydrochloride and serratiopeptidase: Pharmaceutical and mechanical analysis. Int J Pharm Investig 2014;4:5-14.

24. Nirale NM, Menon MD. Topical formulations of serratiopeptidase: Development and pharmacodynamic evaluation. Indian J Pharm Sci 2010;72:65-71.

25. Shinde UA, Kanojiya SS. Serralysin niosomal gel with potential in topical delivery. J Pharm (Cairo) 2014;2014:1-9.

26. Doerr M, Traub WH. Purification and characterization of two Serratia marcescens proteases, zentralblatt fuer bakteriologie, mikrobiologie und hygiene, series A: Medical microbiology, infectious diseases, virology. Parasitology 1984;257:6-19.

27. Dominique L, Markus K, Jean W. Spectrophotometric assay for amidolytic activity of alkaline protease from Pseudomonas aeruginosa. Anal Chim Acta 1997;345:219-25.

28. Pandya EJ, Kapupara P, Shah KV. Development and validation of simultaneous estimation of diclofenac potassium, paracetamol and serratiopeptidase by first order derivative UV spectroscopy method in pharmaceutical formulation. J Chem Pharm Res 2014;6:912-24.

29. Patel RA, Joshi SH. Development and validation of spectrophotometric methods for simultaneous estimation of diclofenac sodium and serratiopeptidase in pharmaceutical dosage form. World J Pharm Pharm Sci 2014;3:1279-91.

30. Parmar AR, Bhakhar DN, Shah DK, Vekariya KV. Simultaneous estimation of aceclofenac and serratiopeptidase in tablet dosage form by absorbance ratio method using visible spectrophotometry. Pharm Sin 2012;3:321-6.

31. Singh D, Saraf S, Dixit VK, Singh D, Singh M. Spectrophotometric determination of serratiopeptidase and Metronidazole in combined dosage. Biosci Biotech Res Asia 2007;4:305-6.

32. Rakibe VD, Kapse SN, Mahajan S. Simultaneous estimation of serratiopeptidase and diclofenac sodium by UV spectrophotometric method. J Curr Pharm Res 2014;4:1297-301.

33. Limbasiya AB, Kapupara PP, Shah K. Development and validation of analytical method for simultaneous estimation of diclofenac potassium and serratiopeptidase in pharmaceutical formulation. Res J Pharm
Technol 2014;7:655-9.

34. Daharwal SJ, Saraf S. Derivative spectrophotometric method for simultaneous estimation of nimesulide and Serralysin from tablet dosage form. Anal Chem Indian J 2007;5:137-40.

35. Rawat M, Saraf S. Influence of selected formulation variables on the preparation of enzyme-entrapped eudragit S100 microspheres. AAPS PharmSciTech 2007;8:289-97.

36. Hiroshi M, Kazuyuki M. Serralysin and related bacterial proteinases. Methods Enzymol 1995;248:395-413.

37. Yoshiyuki T, Yuki O, Yuya Y. Development of a highly sensitive enzyme immunoassay for serrapeptase and its accuracy. Seibutsu Shiryo Bunseki 2010;33:260-6.

38. Louis D, Sorlier P, Wallach J. Quantitation and enzymatic activity of the alkaline protease from Pseudomonas aeruginosa in culture supernatants from clinical strains. Clin Chem Lab Med 1998;36:295-8.

39. Moriya N, Nakata M, Nakamura M, Takaoka M, Iwasa S, Kato K, et al. Intestinal absorption of serrapeptase (TSP) in rats. Biotechnol Appl Biochem 1994;20:101-8.

40. Miyata K, Tsuda M, Tomoda K. Determination of serratia protease by radioimmunoassay. Anal Biochem 1980;101:332-28.

41. Mathew ST, Devi SG, Sandhya KV. Quantitation of serrapeptase in formulations by UV method in the microplate format. Curr Drug Deliv 2008;5:303-5.

42. Koyama H, Ikemoto T, Itoh S, Hirai S, Kitamori N. Pharmaceutical determination of serrapeptase by high-performance liquid chromatography using gel filtration column. Takeda Kenkyushoho 1989;48:72-7

43. Louis D, Bernillon J, Paisse JO, Wallach JM. Use of liquid chromatography-mass spectrometry coupling for monitoring the serratiopeptidase-catalyzed hydrolysis of a peptide library. J Chromatogr B 1999;732:271-6.

44. Kingsley GR. The direct biuret method for the determination of serum proteins as applied to photoelectric and visual colorimetry. J Lab Clin Med 1942;27:840.

45. Mehl JW. The biuret reaction of proteins in the presence of ethylene glycol. J Biol Chem 1944;157:173.

46. Weichselbaum TE. An accurate and rapid method for the determination of proteins in small amounts of blood serum and plasma. Am J Clin Pathol 1946;10:40-9.

47. Gornall AG, Bardawill CJ, David MM. Determination of serum proteins by means of the biuret reaction. J Biol Chem 1949;177:751-66.

48. Folin O, Ciocalteu V. On tyrosine and tryptophane determinations in proteins. J Biol Chem 1927;73:627-50.

49. Hesin WU. Contribution to the chemistry of phosphomolybdic acids, phosphotungstic acids and allied substances. J Biol Chem 1920;43:189.

50. Ohnishi ST, Barry JK. A simplified method of quantitating protein using the biuret and phenol reagents. Anal Biochem 1978;86:193-200. 